\title{
Longitudinal analysis of quality of life following treatment with Asunercept plus reirradiation versus reirradiation in progressive glioblastoma patients
}

\author{
Wolfgang Wick ${ }^{1} \cdot$ Andriy Krendyukov $^{2} \mathbb{C} \cdot$ Klaus Junge $^{3} \cdot$ Thomas Höger $^{2} \cdot$ Harald Fricke $^{2}$
}

Received: 22 August 2019 / Accepted: 19 October 2019 / Published online: 2 November 2019

(c) The Author(s) 2019

\begin{abstract}
Purpose Glioblastoma is an aggressive malignant cancer of the central nervous system, with disease progression associated with deterioration of neurocognitive function and quality of life (QoL). As such, maintenance of QoL is an important treatment goal. This analysis presents time to deterioration $(\mathrm{TtD})$ of $\mathrm{QoL}$ in patients with recurrent glioblastoma receiving Asunercept plus reirradiation (rRT) or rRT alone.

Methods Data from patients with a baseline and $\geq 1$ post-baseline QoL assessment were included in this analysis. TtD was defined as the time from randomisation to the first deterioration in the EORTC QLQ-C15, PAL EORTC QLQ-BN20 and Medical Research Council (MRC)-Neurological status. Deterioration was defined as a decrease of $\geq 10$ points from baseline in the QLQ-C15 PAL overall QoL and functioning scales, an increase of $\geq 10$ points from baseline in the QLQ-C15 PAL fatigue scale and the QLQ-BN20 total sum of score, and a rating of "Worse" in the MRC-Neurological status. Patients without a deterioration were censored at the last QoL assessment. Kaplan-Meier estimates were used to describe TtD and treatment groups (Asunercept + rRT or rRT alone) were compared using the log-rank test.

Results Treatment with Asunercept $+\mathrm{rRT}$ was associated with significant improvement of TtD compared with $\mathrm{rRT}$ alone for QLQ-CL15 PAL overall QoL and physical functioning, and MRC Neurological Status ( $\mathrm{p} \leq 0.05)$. In the Asunercept $+\mathrm{rRT}$ group, QoL was maintained beyond progresison of disease (PoD).

Conclusion Treatment with Asunercept plus rRT significantly prolongs TtD and maintains QoL versus rRT alone in recurrent glioblastoma patients.
\end{abstract}

Keywords Asunercept $\cdot$ Recurrent glioblastoma $\cdot$ Quality of life $\cdot$ Time to deterioration

\section{Introduction}

Glioblastoma (GB) is the most aggressive malignant cancer of the central nervous system and accounts for $>60 \%$ of adult brain tumours [1]. Median survival from time of GB diagnosis is $14-15$ months [2, 3], and disease progression is

Harald Fricke is former employee of Apogenix AG.

Andriy Krendyukov

andriy.krendyukov@apogenix.com

1 Department of Neurology and Neurooncology Program, National Center for Tumor Diseases, Heidelberg University Hospital, Heidelberg, Germany

2 Apogenix AG, Heidelberg, Germany

3 Scope International AG, Mannheim, Germany often associated with a gradual deterioration of neurocognitive function, quality of life (QoL) and functional independence [4]. No treatment standard exists for GB at progression, but available therapeutic strategies include reoperation, reirradiation (rRT), alkylating chemotherapy with temozolomide or nitrosoureas (such as lomustine), bevacizumab, and experimental agents used within clinical trials [5-9]. With the absence of standard therapy, enrolment into clinical trials is recommended by guidelines as the preferred treatment approach $[6-8,10,11]$. This highlights the urgent need for new innovative approaches for the treatment of recurrent GB (rGB).

Activation of the CD95 (Fas)/CD95L (Fas ligand) signaling pathway plays an important role in invasive growth and migration in GB [5, 12-15]. Asunercept/APG 101 is a recombinant glycosylated fusion protein that consists of the extracellular domain of human CD95 linked to the Fc 
Table 1 QoL deterioration and median TtD following treatment with either rRT + Asunercept or rRT alone

\begin{tabular}{|c|c|c|c|c|c|}
\hline & \multicolumn{2}{|c|}{$\begin{array}{l}\text { Asuner- } \\
\text { cept +rRT }\end{array}$} & \multicolumn{2}{|c|}{ rRT } & \multirow[t]{2}{*}{$\mathrm{p}$ value } \\
\hline & $\mathrm{N}$ & $\begin{array}{l}\text { Median } \\
\text { TtD, } \\
\text { days }\end{array}$ & $\mathrm{N}$ & $\begin{array}{l}\text { Median } \\
\text { TtD, } \\
\text { days }\end{array}$ & \\
\hline \multicolumn{6}{|l|}{ QLQ-CL15 PAL } \\
\hline Overall QoL & 49 & 166 & 21 & 107 & 0.0099 \\
\hline Physical functioning & 53 & 183 & 22 & 89 & 0.0069 \\
\hline Emotional functioning & 50 & NR & 21 & 117 & 0.3002 \\
\hline Fatigue & 50 & 98 & 21 & 88 & 0.5956 \\
\hline QLQ-BN20 total score & 52 & NR & 22 & 139 & 0.5419 \\
\hline $\begin{array}{l}\text { MRC neurological } \\
\text { status }\end{array}$ & 57 & 166 & 25 & 103 & 0.0319 \\
\hline
\end{tabular}

$N R$ not reached

domain of human IgG1. It was designed to selectively bind to CD95L and thereby disrupt CD95/CD95L interaction. The scientific rationale for Asunercept in recurrent glioblastoma is supported by a number of in vitro and in vivo nonclinical

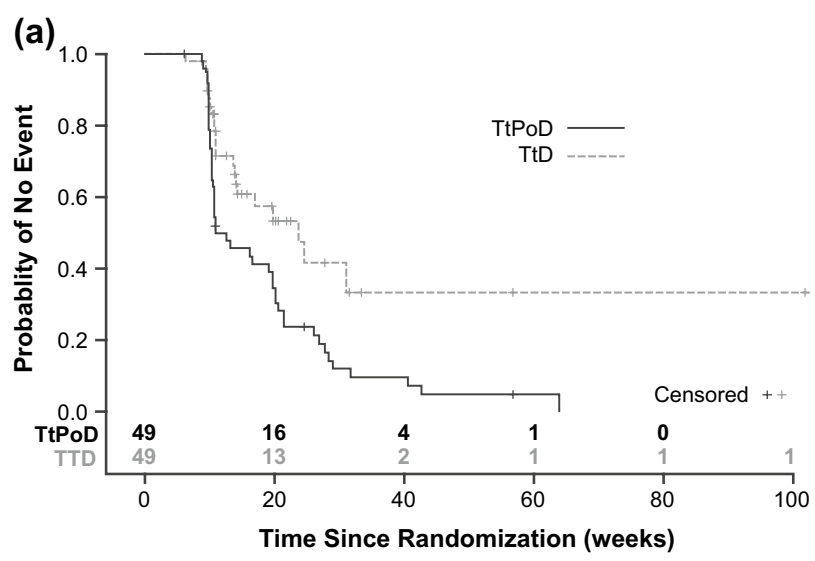

(b)

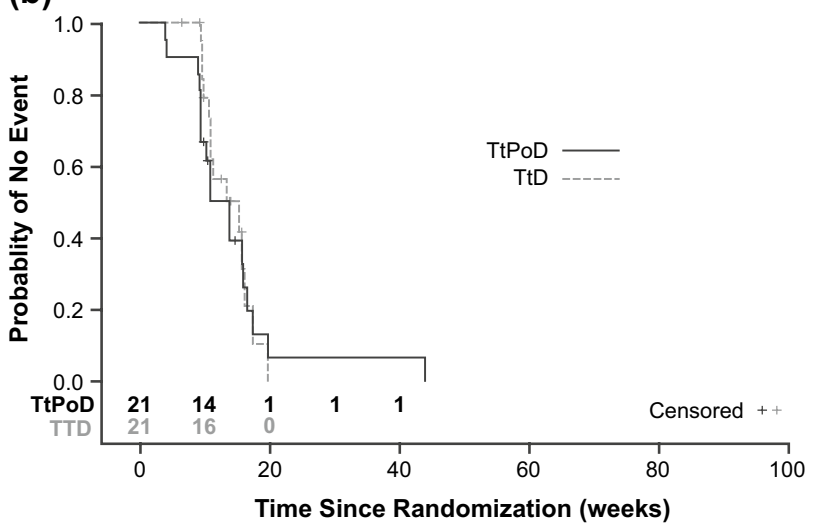

Fig. 1 Kaplan-Meier curves showing TtPoD and TtD of overall QLQ-CL15 PAL in patients treated with Asunercept + rRT (a) or rRT alone (b)
Fig. 2 Kaplan-Meier curves showing effect of Asunercept +rRT and rRT alone on TtPoD and TtD in physical functioning (a, e) neurological status $(\mathbf{b}, \mathbf{f})$, fatigue $(\mathbf{c}, \mathbf{g})$ and total sum of all scores $(\mathbf{d}, \mathbf{h})$

studies that show its enhanced effect when administered in combination with radiotherapy $[13,15]$. A Phase II clinical trial (NCT01071837) aimed to assess the combination of Asunercept with rRT to support the rationale that Asunercept enhances the efficacy of rRT $[13,15]$. There is evidence that RT temporarily disrupts the blood-brain-barrier [16] and thus may facilitate Asunercept entering the tumour. The study demonstrated improved 6-month progression-free survival (PFS-6) for Asunercept + rRT (20.7\% [95\% confidence interval: $11.2-33.4]$ ) compared with rRT alone (3.8\% [95\% confidence interval: 0.1-19.6]) [5].

The burden of disease in patients with GB is high [17, 18] and has a significant impact on QoL, including sleep disruption, inability to concentrate, depression, financial difficulties, and impaired professional, personal, and social lives [19]. Given the poor prognosis of GB and rGB with currently available treatment options, maintenance of QoL is an important therapeutic goal [6, 7]. Beyond progression-free survival (PFS) and overall survival (OS), maintenance or even improvement of QoL is an important goal of treatment. The current analysis presents time to deterioration (TtD) of QoL in patients with rGB receiving Asunercept $+\mathrm{rRT}$, compared with those receiving rRT alone.

\section{Methods}

This Phase II study (NCT01071837) followed a Simon twostage design. Methods and primary and secondary outcome results have been previously published [5]. In brief, a randomised control arm with rRT alone was added to avoid under- or overestimation of a signal from Asunercept [5]. Patients $(\mathrm{N}=91)$ with $\mathrm{GB}$ at first or second progression were randomised 1:2 between rRT alone ( $36 \mathrm{~Gy}$; five times 2 Gy per week) or rRT + Asunercept (400 mg weekly as a 30-minute i.v. infusion) [5]. Seven patients dropped out without receiving study treatment, leaving 84 patients for the Full Analysis Set (FAS). All procedures performed were in accordance with the ethical standards of the institutional and national research committees and with the 1964 Helsinki declaration and its later amendments or comparable ethical standards [5]. All patients were required to give signed informed consent before enrolment.

The current post-hoc analysis assessed TtD of QoL using data from this study. QoL was assessed at baseline and every 6 weeks after the end of rRT until the end of the study, not including follow-up periods. Patients with a baseline and $\geq 1$ post-baseline QoL assessment were included. TtD was defined as the time from randomisation to the first deterioration in 

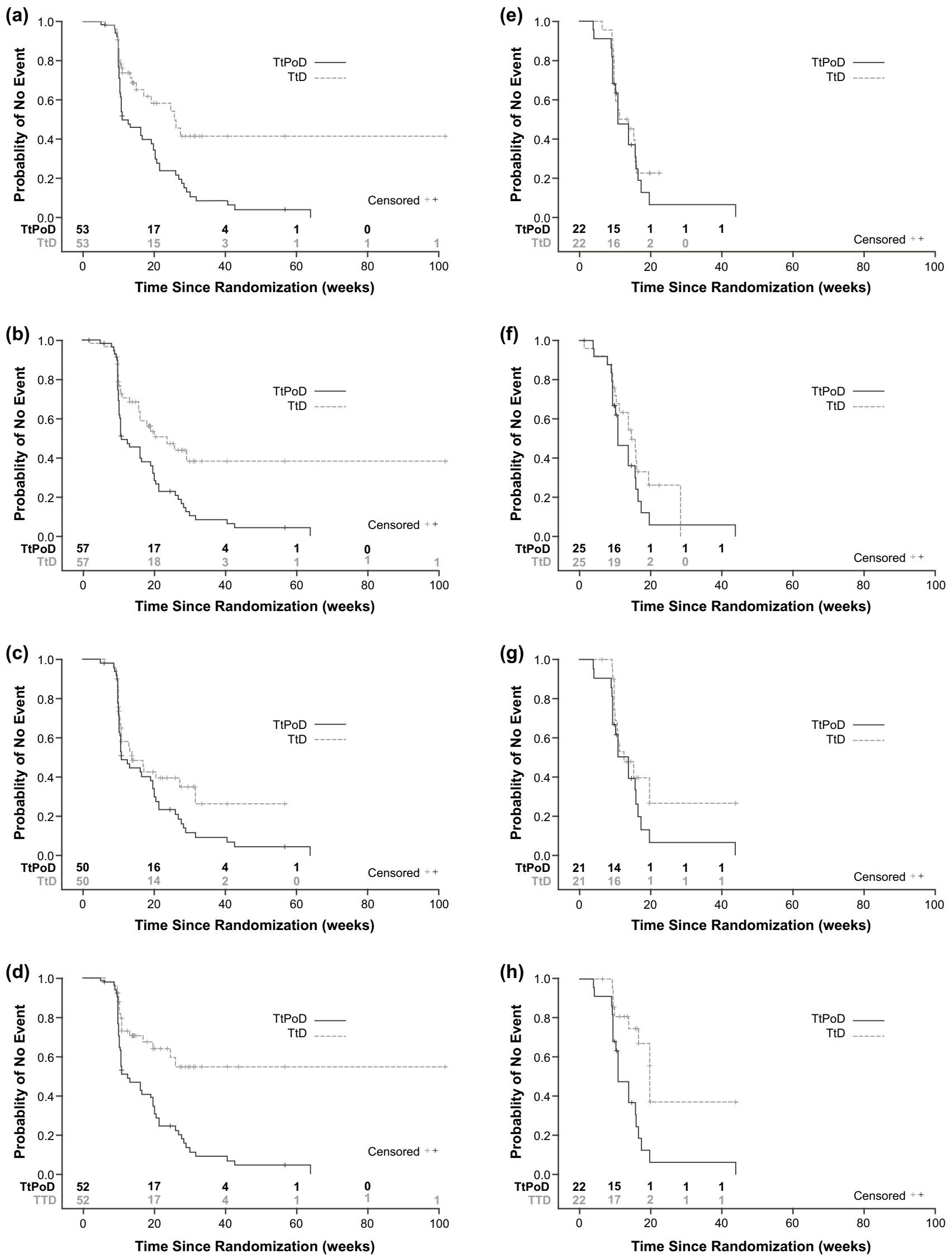
EORTC QLQ-C15 PAL, EORTC QLQ-BN20 and Medical Research Council (MRC)-Neurological status. Deterioration was defined as a decrease of $\geq 10$ points from baseline in the QLQ-C15 PAL overall QoL and functioning scales, an increase of $\geq 10$ points from baseline in the QLQ-C15 PAL fatigue scale and the QLQ-BN20 total sum score, and a rating of "Worse" in the MRC-Neurological status. Patients without deterioration were censored at the last QoL assessment [20, 21]. Kaplan-Meier estimates were used to describe TtD and both treatment groups were compared using the log-rank test. The relationship between time to progression of disease (TtPoD) and QoL deterioration was also investigated.

The study followed the Declaration of Helsinki and the Guideline for Good Clinical Practice (ICH-GCP).

\section{Results}

Baseline patient characteristics including age and sex were generally well balanced between treatment groups and have previously been reported elsewhere [5]. Disease characteristics were also similar between groups, including Karnofsky performance status, recurrence status, median time since first diagnosis, and tumour diameter [5].

Treatment with Asunercept + rRT was associated with significant prolongation of $\mathrm{TtD}$ compared with $\mathrm{rRT}$ alone for QLQ-CL15 PAL overall QoL and physical functioning, and MRC Neurological Status ( $\mathrm{p} \leq 0.05$, Table 1). With Asunercept + rRT, overall QoL was maintained until TtD at 166 days (vs. 107 days with $\mathrm{rRT}, \mathrm{pp}=0.0099$ ), and physical functioning was maintained until TtD at 183 days (vs. 89 days with $r R T, p=0.0069)$. MRC neurological status with Asunercept + rRT was maintained until TtD at 166 days (vs. 103 days with rRT, $p=0.0319$ ). In the Asunercept + rRT group, QoL was maintained beyond $\mathrm{PoD}$, as the proportion of patients without deterioration of QoL was considerably greater than the proportion of progression-free patients (Fig. 1a). In the rRT group the two curves nearly overlay, indicating a dependency between progression and QoL deterioration (Fig. 1b) A prolonged effect of Asunercept $+\mathrm{rRT}$ on QoL beyond PoD was observed for all scores (Fig. 2a-d). For fatigue and total sum of scores (Brain Cancer Module 20 [BN20]), similar effects were also observed for treatment with rRT alone (Fig. 2g, h, Table 1).

\section{Discussion}

Due to the limited number of available therapies with substantial impact on PFS and OS in $\mathrm{rGB}$, the maintenance of QoL has emerged as an important endpoint to reduce morbidity, preserve neurologic functions, and sustain the capacity to perform daily activities [22]. Compared with rRT alone, treatment with a combination of Asunercept $+\mathrm{rRT}$ was associated with a significant prolongation of $\mathrm{TtD}$ and maintenance of QoL. Disease progression is seen as a key event driving QoL deterioration, and the median TtD was comparable with PFS in both treatment arms. However, in patients receiving Asunercept $+\mathrm{rRT}$ the $\mathrm{TtD}$ was prolonged beyond progression of the disease; this was not the case in patients treated with rRT alone. In none of the scores examined did treatment with Asunercept have a negative impact on patient performance/QoL.

In the current study, PFS- 6 and OS for Asunercept + rRT were in line with Phase II/III studies of approved treatments for rGB [23-25]. QoL is a key consideration in studies of $\mathrm{rGB}$, and, as such, other studies of approved interventions have also assessed the relationship between TtPoD and QoL deterioration, as summarised in Table 2. A Phase III study in which patients with $\mathrm{rGB}$ were randomised to receive lomustine plus bevacizumab $(\mathrm{N}=288)$ or lomustine alone $(\mathrm{N}=149)$ reported no significant difference in $\mathrm{TtD}$ in QoL between groups when progression was not included as an event [26]. Nonetheless, deterioration-free survival was longer in the combination group than in the monotherapy group (12.4 weeks vs. 6.7 weeks; $p p<0.001$ ), reflecting the difference in time to progression [26]. CABERET, a Phase II trial of bevacizumab and carboplatin $(\mathrm{N}=122)$ in rGB, reported that decreases in health-related QoL generally occurred before disease progression [27]. Despite this, QoL domains considered relevant to symptoms of rGB improved in half of the patients who had symptoms at baseline [27]. There were no differences between patients receiving bevacizumab alone and those given carboplatin [27]. A Phase II study comparing temozolomide $(\mathrm{N}=112)$ with procarbazine $(\mathrm{N}=113)$ in patients with rGB showed that, regardless of the treatment, QoL was maintained at baseline levels prior to PoD but then decreased substantially at the time of PoD [24]. In light of these studies, it is of note that our Phase II study demonstrated that, in addition to improved PFS-6, Asunercept $+\mathrm{rRT}$ maintained QoL beyond PoD, particularly within the domains of general QoL, physical functioning and MRC neurological status. In the current study, approximately half of the patients in each arm received bevacizumab after disease progression, as per the investigator's choice, with different doses and durations of its administration. Our study did not include a QoL assessment specifically on bevacizumab, and thus we can neither confirm nor exclude its impact on QoL. Available data from published studies on bevacizumab do not support either prolonged OS or QoL (Table 2). This suggests that further studies are needed to fully explore how bevacizumab affects QoL in rGB.

A meta-analysis using data from 15 RCTs including 5217 patients was performed to investigate the added prognostic value of heath-related QoL for OS and PFS in glioma patients [28]. The study reported that factors including better 


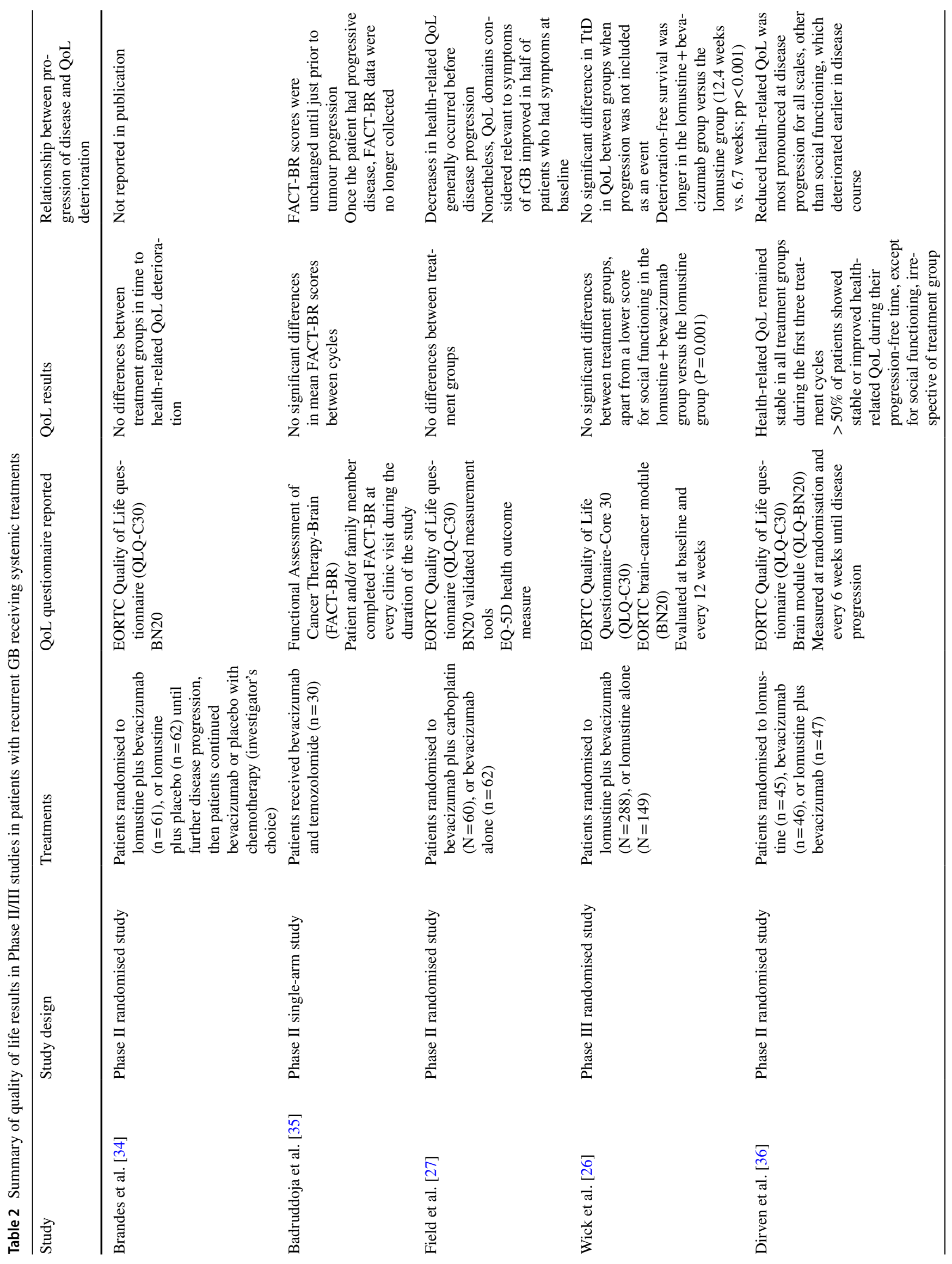




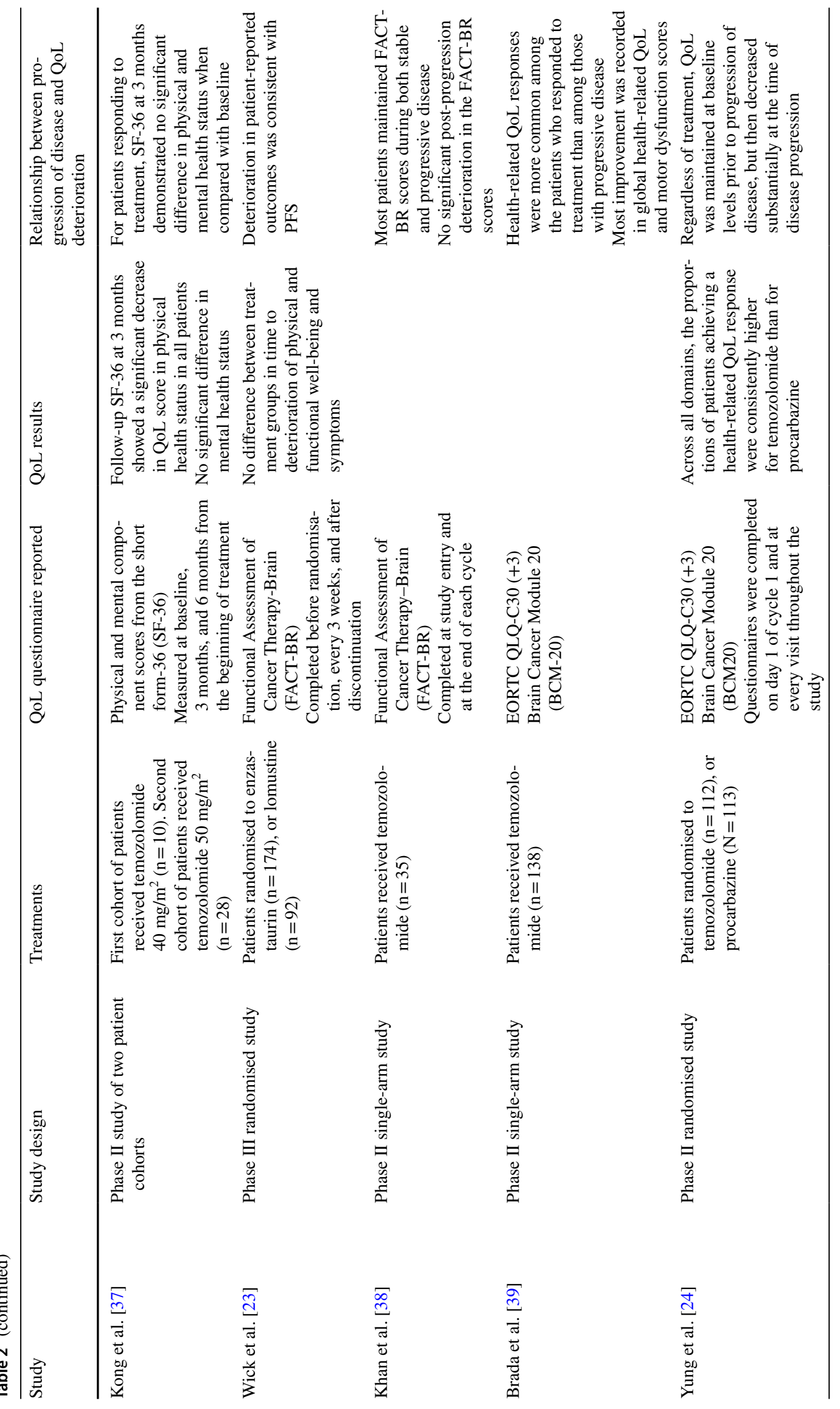


cognitive and role functioning and less motor dysfunction were independently associated with prolonged OS [28]. Factors including better role and cognitive functioning, and less nausea and vomiting were independently associated with prolonged PFS [28].

Regarding the impact of different radiation schedules on outcomes in patients with GB, a recent study [29] used data from the National Cancer Database to identify patients with GB who underwent surgical resection and external-beam radiation with chemotherapy. The findings showed that dose-escalated radiotherapy has decreased with time in GB patients in the US, as supported by clinical guidelines [30, 31]. The study did not identify differences in survival between patients receiving conventional doses, and those receiving higher doses (>66 Gy). A recent multiple linear regression analysis of publications from 1992 to 2016 investigated the relationship between re-irradiation and median OS [32]. Findings suggested that OS was highest after re-irradiation with single-fraction stereotactic radiosurgery, followed by hypofractionated stereotactic radiotherapy, and conventionally fractionated radiotherapy. Reporting of health-related QoL outcomes remains an unmet need in rGB trials - this was not reported in these studies.

There are limitations to comparing QoL results between different studies due to factors including use of different scales, relevance of the domains included in the scales to the patient population, and differences in timing for when QoL measures were made. Table 3 summarises three of the most frequently used scales: EORTC QLQC30, BN20, and Assessment of Cancer Therapy-Brain (FACT-BR). Our study utilised the EORTC QLQ-C15PAL questionnaire, which is designed to assess QoL in palliative care cancer patients and includes certain domains and symptoms of EORTC QLQ-C30: overall QoL, physical, emotional and fatigue. As such, this scale was more suitable for the patient population included in the current study. The FACT-BR and BN20 questionnaires were designed specifically for patients with brain tumours. FACT-BR largely focuses on emotional and social functioning and as such may be more useful in patients with good functional status but who have emotional and social concerns [33]. Used with QLQ-C30 or QLQ-C15-PAL, BN20 may provide a broader evaluation of QoL in studies concerned with functional status that might affect QoL [33]. Nonetheless, both of these questionnaires, and others used in studies of QoL in recurrent GB, are valid, have been used extensively and provide reliable results. A further limitation of our, and all other published data so far, is the lack of health-related QoLfollow-up after progression and the number of completed follow-up visits, even in larger trials. 


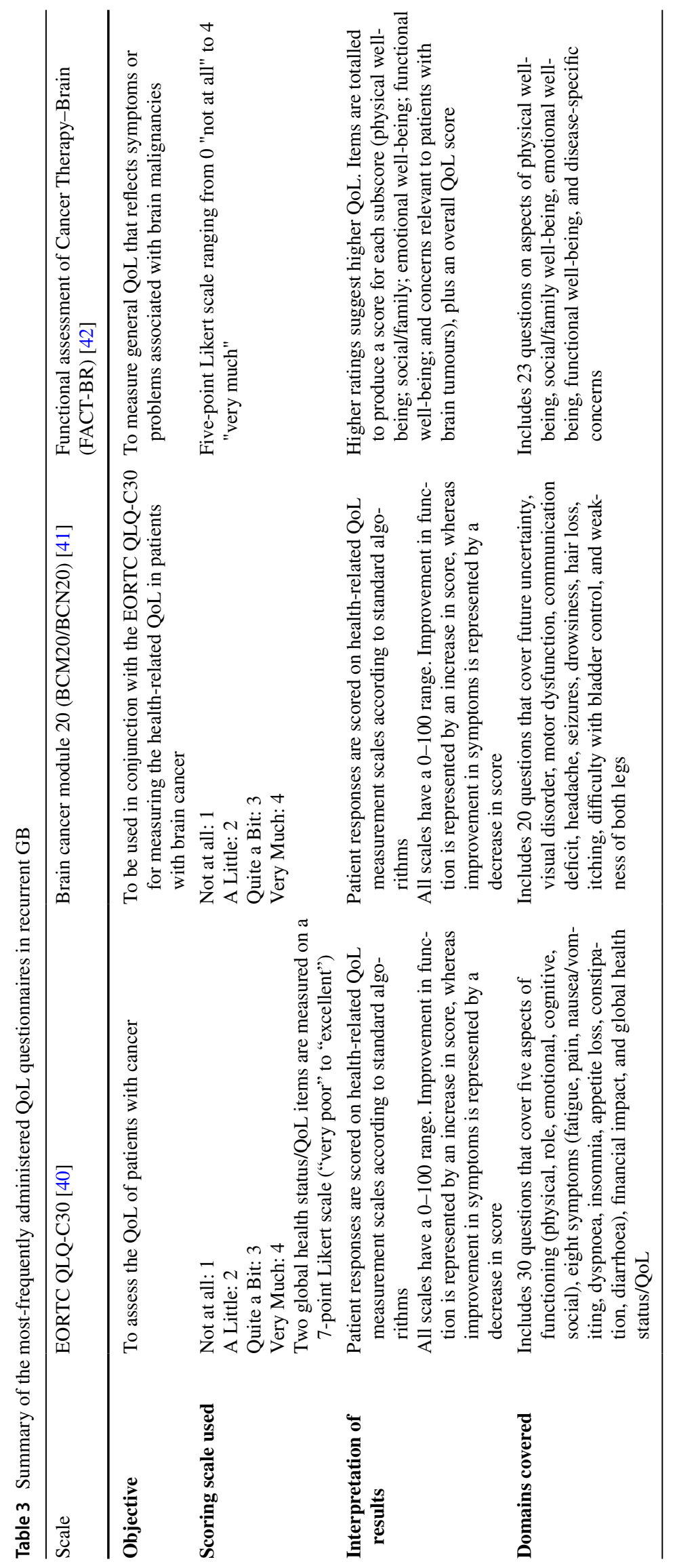




\section{Conclusion}

In patients with $\mathrm{rGB}$, treatment with Asunercept + rRT significantly prolongs TtD and maintains QoL versus rRT alone.

Acknowledgements The authors would like to thank Drs K. Schmieder, R. Wurm, C. Weiss, O. Heese, T. Martens, T. Wiegel, U. Schlegel, R. D. Kortmann, U. Herrlinger, C. Belka, M. Nadji-Ohl, P. Hau, C. Lumenta, C. Beier, S. Astner, C. Marosi, W. Grisold, F. Payer, J. Pichler, G. Stockhammer, G. Kobyakov, S. Tkachev, O. Dreval, T. Chuprik-Malinovskaya, M. Kopp, I. Poverennova, V. Kosenok, D. Svistov as study investigators, patients and their families, Dr J. Debus, Dr M. Bendszus, and Dr C. Kunz. Editorial support was provided by Caroline McGown of Spirit Medical Communications Group Ltd., supported by Apogenix AG. Final approval of the manuscript rested solely with the scientific authors.

Author contributions All authors contributed to the study conception and design. Data collection was performed by all authors. Data analysis was performed by Klaus Junge. All authors were responsible for the writing of the manuscript. All authors read and approved the final manuscript.

Funding This study was supported by Apogenix AG.

Data availability Data generated or analysed during and after this study are included in this and previously published articles.

\section{Compliance with ethical standards}

Conflict of interest Wolfgang Wick reports receiving a commercial research grant from Boehringer Ingelheim and Roche; speaker's bureau honoraria from Prime Oncology; and is a consultant/advisory board member for Eli Lilly and Co. and Roche. Andriy Krendyukov and Thomas Höger are employees of Apogenix. No potential conflicts of interest were disclosed by Klaus Junge.

Ethical approval All procedures performed in studies involving human participants were in accordance with the ethical standards of the institutional and national research committees and with the 1964 Helsinki declaration and its later amendments or comparable ethical standards.

Informed consent Informed consent was obtained from all individual participants included in the study at the time of study conduct.

Open Access This article is distributed under the terms of the Creative Commons Attribution 4.0 International License (http://creativeco mmons.org/licenses/by/4.0/), which permits unrestricted use, distribution, and reproduction in any medium, provided you give appropriate credit to the original author(s) and the source, provide a link to the Creative Commons license, and indicate if changes were made.

\section{References}

1. Rock K, McArdle O, Forde P et al (2012) A clinical review of treatment outcomes in glioblastoma multiforme: the validation in a non-trial population of the results of a randomised phase III clinical trial: has a more radical approach improved survival? Br J Radiol 85:e729-e733

2. Ohka F, Natsume A, Wakabayashi T (2012) Current trends in targeted therapies for glioblastoma multiforme. Neurol Res Int 2012:878425

3. Thakkar JP, Dolecek TA, Horbinski C et al (2014) Epidemiologic and molecular prognostic review of glioblastoma. Cancer Epidemiol Biomark Prev 23(10):1985-1996

4. Chinot OL, Wick W, Mason W et al (2014) Bevacizumab plus radiotherapy-temozolomide for newly diagnosed glioblastoma. $\mathrm{N}$ Engl J Med 370(8):709-722

5. Wick W, Fricke H, Junge K et al (2014) A phase II, randomized, study of weekly APG101+reirradiation versus reirradiation in progressive glioblastoma. Clin Cancer Res 20(24):6304-6313

6. NCCN (2019) Central nervous system cancers. Version 2019.1

7. Stupp R, Brada M, van den Bent MJ et al (2014) High-grade glioma: ESMO clinical practice guidelines for diagnosis, treatment and follow-up. Ann Oncol 25(S3):93-101

8. Weller M, van den Bent M, Tonn JC et al (2017) European Association for Neuro-Oncology (EANO) guideline on the diagnosis and treatment of adult astrocytic and oligodendroglial gliomas. Lancet Oncol 18(6):e315-e329

9. NICE (2018) Brain tumours (primary) and brain metastases in adults. NICE guideline [NG99]. https://www.nice.org.uk/guida nce/ng99. Accessed 11 July 2019

10. Martínez-Garcia M, Álvarez-Linera J, Carrato C et al (2018) SEOM clinical guidelines for diagnosis and treatment of glioblastoma (2017). Clin Transl Oncol 20(1):22-28

11. Gallego O (2015) Nonsurgical treatment of recurrent glioblastoma. Curr Oncol 22(4):e273-e281

12. Peter ME, Krammer PH (2003) The CD95(APO-1/Fas) DISC and beyond. Cell Death Differ 10(1):26-35

13. Kleber S, Sancho-Martinez I, Wiestler B, Beisel A, Gieffers C, Hill O et al (2008) Yes and PI3K bind CD95 to signal invasion of glioblastoma. Cancer Cell 13(3):235-248

14. Merz C, Strecker A, Sykora J, Hill O, Fricke H, Angel P et al (2015) Neutralization of the CD95 ligand by APG101 inhibits invasion of glioma cells in vitro. Anticancer Drugs 26(7):716-727

15. Blaes J, Thomé CM, Pfenning PN et al (2018) Inhibition of CD95/ CD95L (FAS/FASLG) signaling with APG101 prevents invasion and enhances radiation therapy for glioblastoma. Mol Cancer Res 16(5):767-776

16. van Vulpen M, Kal HB, Taphoorn MJ, El-Sharouni SY (2002) Changes in blood-brain barrier permeability induced by radiotherapy: implications for timing of chemotherapy? (Review). Oncol Rep 9(4):683-688

17. Osoba D, Brada M, Prados MD, Yung WK (2000) Effect of disease burden on health-related quality of life in patients with malignant gliomas. Neuro-Oncology 2:221-228

18. Davies E, Clarke C, Hopkins A (1996) Malignant cerebral glioma-I: survival, disability, and morbidity after radiotherapy. BMJ 313:1507-1512

19. Solanki C, Sadana D, Arimappamagan A et al (2017) Impairments in Quality of life and cognitive functions in long-term survivors of glioblastoma. J Neurosci Rural Pract 8(2):228-235

20. Taphoorn MJB, Henriksson R, Bottomley A et al (2015) Healthrelated quality of life in a randomized phase III study of bevacizumab, temozolomide, and radiotherapy in newly diagnosed glioblastoma. J Clin Oncol 33:2166-2175

21. Taphoorn MJ, Stupp R, Coens C et al (2005) Health-related QoL in patients with glioblastoma: a randomised controlled trial. Lancet Oncol 6:937-944

22. Henriksson R, Asklund T, Poulsen HS (2011) Impact of therapy on quality of life, neurocognitive function and their correlates in glioblastoma multiforme: a review. J Neurooncol 104(3):639-646 
23. Wick W, Puduvalli VK, Chamberlain MC et al (2010) Phase III study of enzastaurin compared with lomustine in the treatment of recurrent intracranial glioblastoma. J Clin Oncol 28:1168-1174

24. Yung WK, Albright RE, Olson J, et al (2000) A phase II study of temozolomide vs. procarbazine in patients with glioblastoma multiforme at first relapse. Br J Cancer 83(5):588-593.

25. Friedman HS, Prados MD, Wen PY et al (2009) Bevacizumab alone and in combination with irinotecan in recurrent glioblastoma. J Clin Oncol. 27(28):4733-4740

26. Wick W, Gorlia T, Bendszus M et al (2017) Lomustine and bevacizumab in progressive glioblastoma. N Engl J Med 377(20):1954-1963

27. Field KM, King MT, Simes J et al (2017) Health-related quality of life outcomes from CABARET: a randomized phase 2 trial of carboplatin and bevacizumab in recurrent glioblastoma. J Neurooncol 133(3):623-631

28. Coomans M, Dirven L, Aaronson NK, et al (2019) The added value of health-related quality of life as a prognostic indicator of overall survival and progression-free survival in glioma patients: a meta-analysis based on individual patient data from randomised controlled trials. Eur J Cancer 116:190-198

29. Wegner RE, Abel S, Horne ZD et al (2019) National trends in radiation dose escalation for glioblastoma. Radiat Oncol $\mathrm{J}$ 37(1):13-21

30. Cabrera AR, Kirkpatrick JP, Fiveash JB et al (2016) Radiation therapy for glioblastoma: executive summary of an American Society for Radiation Oncology Evidence-Based Clinical Practice Guideline. Pract Radiat Oncol 6(4):217-225

31. Niyazi M, Brada M, Chalmers AJ et al (2016) ESTRO-ACROP guideline "target delineation of glioblastomas". Radiother Oncol 118(1):35-42

32. Shanker M, Chua B, Bettington C et al (2019) Re-irradiation for recurrent high-grade gliomas: a systematic review and analysis of treatment technique with respect to survival and risk of radionecrosis. Neurooncol Pract 6(2):144-155

33. Chow R, Lao N, Popovic M et al (2014) Comparison of the EORTC QLQ-BN20 and the FACT-Br quality of life questionnaires for patients with primary brain cancers: a literature review. Support Care Cancer 22(9):2593-2598

34. Brandes AA, Gil-Gil M, Saran F et al (2019) A Randomized phase II trial (TAMIGA) evaluating the efficacy and safety of continuous bevacizumab through multiple lines of treatment for recurrent glioblastoma. Oncologist 24(4):521-528

35. Badruddoja MA, Pazzi M, Sanan A et al (2017) Phase II study of bi-weekly temozolomide plus bevacizumab for adult patients with recurrent glioblastoma. Cancer Chemother Pharmacol 80(4):715-721

36. Dirven L, van den Bent MJ, Bottomley A et al (2015) The impact of bevacizumab on health-related quality of life in patients treated for recurrent glioblastoma: results of the randomised controlled phase 2 BELOB trial. Eur J Cancer 51(10):1321-1330

37. Kong DS, Lee JI, Kim JH et al (2010) Phase II trial of low-dose continuous (metronomic) treatment of temozolomide for recurrent glioblastoma. Neuro Oncol 12(3):289-296

38. Khan RB, Raizer JJ, Malkin MG, Bazylewicz KA, Abrey LE (2002) A phase II study of extended low-dose temozolomide in recurrent malignant gliomas. Neuro Oncol 4(1):39-43

39. Brada M, Hoang-Xuan K, Rampling R et al (2001) Multicenter phase II trial of temozolomide in patients with glioblastoma multiforme at first relapse. Ann Oncol 12(2):259-266

40. EORTC QLQ-C30 (version 3) (2019) https://www.eortc.org/ app/uploads/sites/2/2018/08/Specimen-QLQ-C30-English.pdf. Accessed 8 Aug 2019

41. EORTC Quality of Life Questionnaire-Brain Cancer Module (EORTC QLQ-BN20) (2019) https://eprovide.mapi-trust.org/instr uments/eortc-quality-of-life-questionnaire-brain-cancer-module. Accessed 8 Aug 2019

42. Functional Assessment of Cancer Therapy-Brain (FACT-Br) (2019) https://www.rtog.org/LinkClick.aspx?fileticket=CEFIw pmDqVA\%3D\&tabid=118. Accessed 8 Aug 2019

Publisher's Note Springer Nature remains neutral with regard to jurisdictional claims in published maps and institutional affiliations. 